\title{
Using microcomputer-based EEG to enable and encourage student-designed projects
}

\author{
GWYNETH HILL BEAGLEY and WALTER K. BEAGLEY \\ Alma College, Alma, Michigan
}

\begin{abstract}
Microcomputer-based electrophysiological recording systems enhance undergraduates' understanding of neural activity and enable them to design independent research projects. The physiological psychology class at Alma College has employed BIOPAC Systems MP100 hardware with AcqKnowledge software and Macintosh computers to record and analyze electroencephalograms (EEG). After examining progressive changes in brain waves during sleep, student researchers have proceeded to study the effects of a variety of factors such as caffeine, cognitive tasks, and prior experiences. The simplicity of the system allows undergraduates to concentrate on experimental design and data analysis rather than instrumentation.
\end{abstract}

Two primary goals of an undergraduate course in physiological psychology are (1) to give students an understanding of the electrical properties of the nervous system, and (2) to have them begin to think scientifically by formulating a question and designing an experiment to answer it. This second goal, called inquiry training by Posner and Osgood (1980), is more difficult and probably more important to a student's education (Beagley, 1993; Eckerman, 1991). At Alma College, we have found that new microcomputer-based electrophysiological recording systems make it possible to use electroencephalography (EEG) to accomplish both goals. The hardware and software are less expensive and easier to use than traditional pen and ink physiographs. And the experience of seeing real-time brain waves from a live human being is sufficiently compelling so that students are motivated to generate their own research questions.

EEG has been an important tool in understanding the brain since the early 1900s (Empson, 1986; Kleitman, 1963). It has been used as a part of laboratory training in psychology (Rivers, Mullington, Stampi, \& Broughton, 1994; Rosen \& Petty, 1992; Scammon, Kennard, Stroebel, \& Glueck, 1981), though it has not been popular, owing to the expense and complexity of the equipment. For more than 20 years, our course has included a sleep demonstration lab where electrode output from the forehead of a sleeping subject is fed into a differential amplifier and then into the deflecting pens of a physiograph. Brain waves from half a night's sleep were recorded on moving rolls of paper. Although it was a good exercise for an undergraduate class, there were limitations, not the least of which was erratic behavior of the ink pens. The session was, moreover, limited to observation only. The students were distanced from the experience by large complex

Correspondence concerning this article should be addressed to $G . H$ Beagley, Department of Psychology, Alma College, Alma, MI 488011599 (e-mail: beagley@alma.edu). equipment being run by the instructor. Their involvement consisted of watching the sleeper and wall-papering the corridors with output from the physiograph.

\section{Hardware and Software}

With the availability of personal computers, EEG can now be monitored with the use of a computer-based data acquisition system. We use BIOPAC Systems MP100 hardware, ${ }^{1}$ with AcqKnowledge software and Macintosh computers. (It is also available for PCs.) The system is simple enough so that undergraduates can run it themselves. The equipment is robust, and the virtual pens never clog up. The minimum software and hardware (for a singlechannel system) costs about the same as a high-end computer $(\$ 3500)$.

The BIOPAC EEG module is a single-channel differential input amplifier with adjustable gain (5000 to 50000 ). It is designed to pass characteristic EEG signal ranges and wave forms. The most basic setup uses two shielded electrodes and one unshielded electrode for ground. The system will accept input from up to 16 separate channels, and there are modules available for a variety of other functions including Electrocardiography, Electromyography, Galvanic Skin Response (GSR), and so forth. The applications of GSR in student laboratories are extensive but are beyond the scope of this paper (see Crider, 1972). Safety features include appropriate isolation of the electrode input module from ac power and the use of disposable electrodes to ensure hygienic conditions. The software enables the researcher to adjust running time so that sessions can last several minutes, as in biofeedback experiments, or several hours, if the students wish to observe a long sleep period. Alma College has a pair of electrically shielded chambers connected by a two-way mirror, but we have found that data can be collected almost anywhere.

The wave form output from the subject can be both observed and saved to disk. By saving a long session as a series of separate files, students can replay, analyze, and 
make printouts from earlier segments while recording continues. In addition to eliminating the ink mess and lengthy paper traces, the program will also measure amplitudes of wave forms and analyze frequency by finding the modal frequency from an FFT analysis or by doing peak to peak counts within a specified time period. These analyses can be performed for the whole session or for selected sections. The time scale is adjustable so that an entire 8-h session can be compressed to a single page to emphasize the cyclical wave pattern changes. Perhaps the most important benefit is that ease of use frees students to concentrate on designing the experiments and analyzing the data.

\section{Lecture, Demonstration, and Short Studies}

Before the laboratory, students are given a lecture containing a detailed explanation of EEG and a demonstration of how to operate the equipment properly. The discussion of EEG involves introduction of the different wave forms and frequencies and what researchers believe they indicate. The lecture includes characteristic changes in EEG during a normal night's sleep: the increase in amplitude and decrease in frequency through the early stages, slow wave, and rapid eye movement (REM) sleep (Carlson, 1994). We also discuss the effects of brain and sleep disorders and the suppression of alpha activity with visual attention (Boudrot, Goodman, \& Mulholland, 1978),

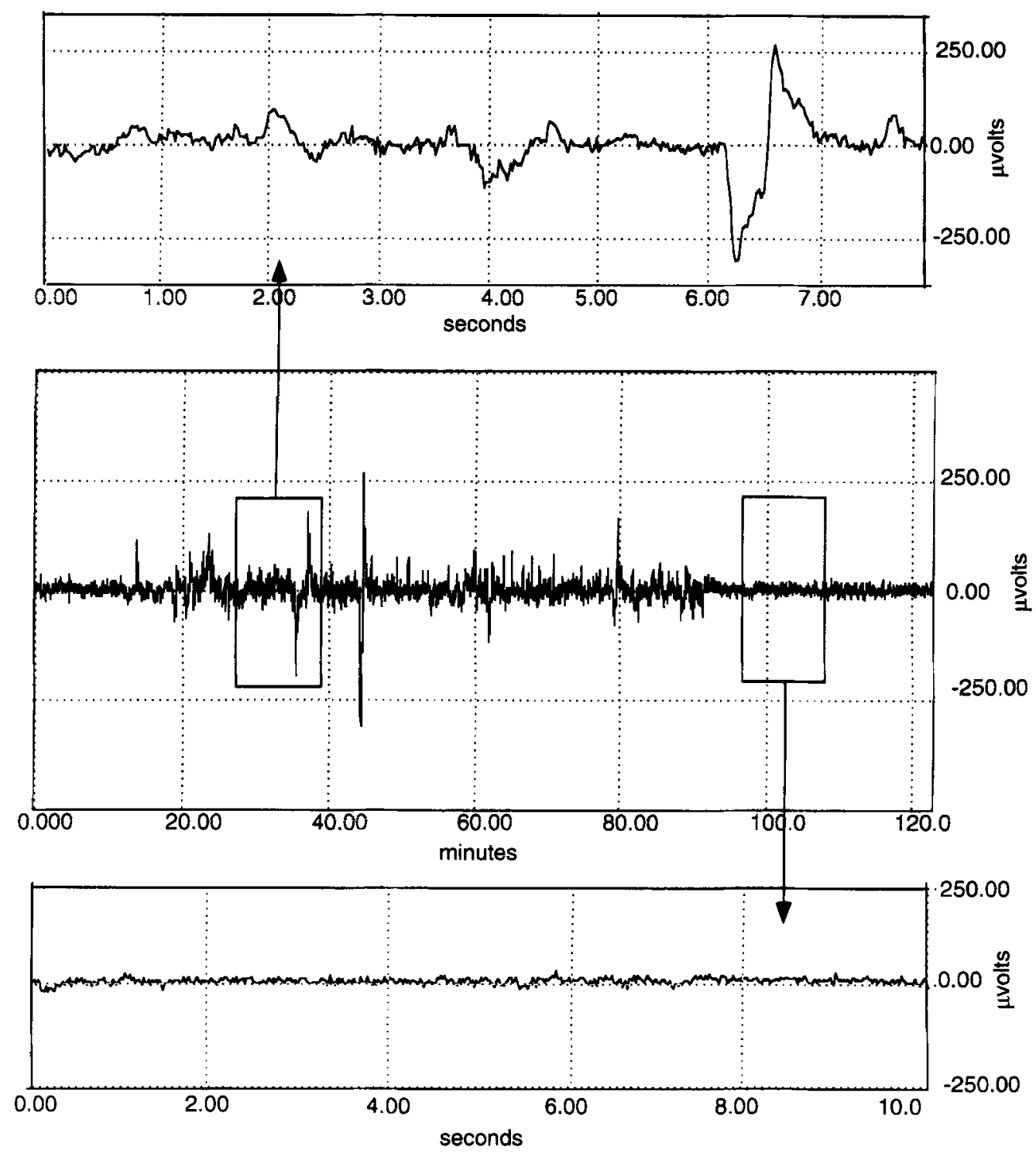

Figure 1. EEG from a student's sleep session: The center graph is a compressed 2-h section of an all-night EEG recording session. It includes sections of mixed slow waves (top graph) and REM (bottom graph), at normal time scale. 
as well as more controversial findings such as biofeedback training to increase alpha or the relationship between brain waves and learning (Johnson, 1977). This grabs the students' attention and elicits from them ideas for conducting EEG experiments of their own.

The simplest demonstration is still a half night observation of wave changes during different stages of sleep. This works amazingly well and even with only two electrodes shows a predictable pattern of increase in slow waves and shifts to REM (see Figure 1). Children make the best subjects, because they have less trouble adapting to the equipment and reaching the deepest stages of sleep. However, most parents are not enthusiastic about having psychologists attach wires to a child's head.

This is followed by simple student-generated experiments, which can be performed fairly rapidly, to provide data for analysis and lab reports. Undergraduates can be very creative and enterprising. Typical examples involve recruiting volunteers to have their EEG recorded during meditation or problem solving, under different types of lighting, while reading different types of books (Johnson, 1977), and under the influence of substances such as Ginkoba (a purported memory enhancing drug) or caffeine (Walsh, 1974). The effects of different types of music on EEG waves is another favorite topic with students. The results have been variable, but many students have found increased amplitude and decreased frequency with music that promotes relaxation and daydreaming.

Project proposals are approved by the Alma College Research Subjects Committee prior to the start of the experiment. Students must assure the committee that participation is truly voluntary, that subjects are not harmed (mentally or physically), and that they are protected with respect to such rights as privacy and access to the knowledge created by the research.

After running subjects, students are required to present their studies in the form of laboratory reports in APA style. The exercise and feedback often alert them to weaknesses in their initial experimental design and help improve the skills involved in generating testable hy-

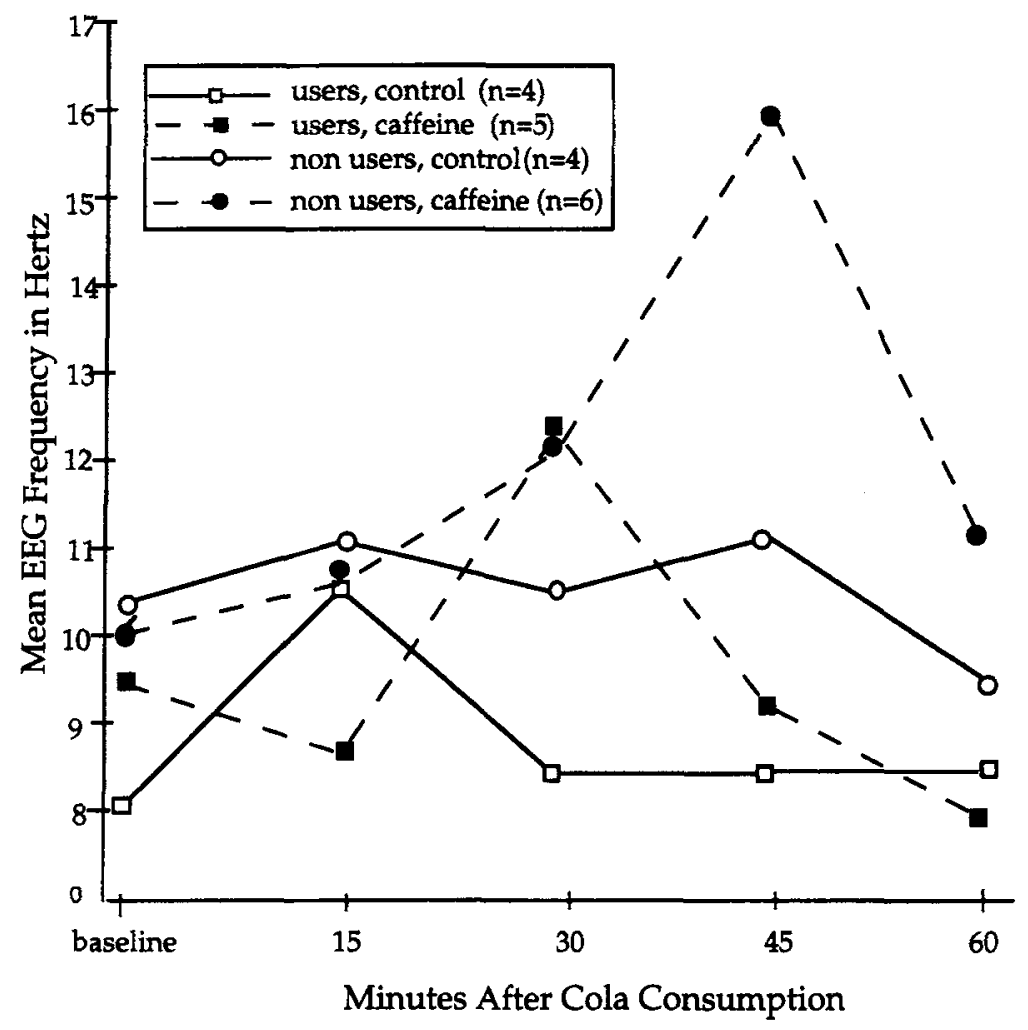

Figure 2. Changes in EEG frequency after caffeine consumption. EEG recordings were made for $45 \mathrm{sec}$ at 15-min intervals after subjects consumed $16 \mathrm{oz}$ of unlabeled caffeinated or caffeine-free cola. Subjects were classified as users if they consumed more than 6 cups of caffeinated beverage per day and nonusers if they did not regularly consume caffeinated beverages. Testing was done at 9:00 a.m., and subjects were asked not to eat or drink before the experiment. Mean frequency for each 45-sec sample was computed with the AcqKnowledge software; means for each condition (subject type, cola type, time after consumption) were then calculated. 
potheses and designing well-controlled experiments. Many students use their preliminary findings as a basis for more sophisticated independent research projects.

\section{Independent Student Projects}

A study examining the effect of caffeine on EEG started as a class project and developed into an independent research project for two 3 rd-year students. The students recruited volunteers who were classified as caffeine users (i.e., they habitually ingested more than 6 caffeine containing drinks per day) or nonusers (they did not habitually drink caffeine). After baseline was taken, subjects were given unlabeled caffeinated or noncaffeinated colas. As is shown in Figure 2, the data suggest different time courses of effects of caffeine on users and nonusers. However, owing to the small sample size, the three-way interaction between user status, caffeine content, and time was not statistically significant $(p=.06)$ in a three-way analysis of variance. (Information on the effects of caffeine on the EEG of human users and nonusers can be found in the work of Christensen, Bourgeois, and Cockroft [1993] and Hasenfratz and Battig [1994].) This experiment led the student researchers to read more about the topic, and the work was presented at a state-wide academic research conference (Sanchez, Miller, \& Beagley, 1997).

Senior theses involve considerably more time and energy, and the BIOPAC/AcqKnowledge apparatus has aided in some fairly impressive undergraduate studies. One student interested in slow-wave sleep disorders wondered whether young adults who reported extensive talking in their sleep would have different slow-wave and REM patterns. His data suggested that sleep talkers may spend longer times in intermediate stages. Another student, who had a personal history of attention deficit/hyperactivity disorder (ADHD), read extensively on the topic and became interested in work by Lubar (1991) and Tansey (1990), who claimed characteristic EEG patterns for individuals with ADHD. This student attempted to duplicate Lubar's findings and did extensive research on electrode placement and cognitive tasks that might show differences in EEG. Data suggested a higher evidence of theta waves (intermediate wave form of about $4-7 \mathrm{~Hz}$ ) when individuals diagnosed with ADHD re challenged with a difficult puzzle (Pestrue, Miller, \& Beagley, 1995).

\section{Conclusions}

We have found this equipment to be a tool which adds flexibility and independence to student labs. It illustrates vividly the important principles of electrical brain activity and motivates students to engage in further research on topics in physiological psychology. Similar success with other psychophysiology systems, such as LabVIEW, has also been reported (Bates, 1991). The important factor is, as emphasized by Castellan (1988), that the computer and software have become tools for the student (rather than the professor); the technology is a servant to real research and inquiry. And though the "yield" of publishable results from these student-initiated projects may be low, nothing else can contribute as much to a student's scientific education.

\section{REFERENCES}

BATES, T. C. (1991). A Macintosh II psychophysiology system. Behavior Research Methods, Instruments, \& Computers, 23, 395-402.

BEAGLEY, W. K. (1993). Eye Lines: Generating data through image manipulation, issues in interface design, and the teaching of experimental thinking. Behavior Research Methods, Instruments, \& Computers, 25, 333-336.

Boudrot, R. L., Goodman, D. M., \& Mulholland, T. B. (1978). An EEG alpha-detection, feedback stimulation, and data analysis system. Behavior Research Methods \& Instrumentation, 10, 646-651.

CarLson, N. R. (1994). Physiology of behavior. Boston: Allyn \& Bacon.

Castellan, N. J., JR. (1988). Comments on applications of microcomputers in teaching. Behavior Research Methods, Instruments, \& Computers, 20, 193-196.

Christensen, L., Bourgeois, A., \& Cockroft, R. (1993). Electroencephalographic concomitants of a caffeine-induced panic reaction. Journal of Nervous \& Mental Disease, 181, 327-330.

CrIDER, A. (1972). Five demonstrations with the GSR: Student lab manual. Perceptual \& Motor Skills, 35, 426-429.

ECKERMAN, D. A. (1991). Microcomputers in undergraduate laboratory training in psychology. Behavior Research Methods, Instruments, \& Computers, 23, 91-99.

EMPSON, J. (1986). Human brainwaves: The psychological significance of the electroencephalogram. New York: Macmillan.

Hasenfratz, M., \& Battig, K. (1994). Acute dose effect relationships of caffeine and mental performance, EEG, cardiovascular and subjective parameters. Psychopharmacology, 114, $281-287$.

JOHNSON, L. (1977). Learned control of brain wave activity. In J. Beatty \& H. Legewie (Eds.), Biofeedback and behavior (pp. 73-94). New York: Plenum.

KLeitman, N. (1963). Sleep and wakefulness. Chicago: University of Chicago Press.

LUBAR, J. F. (1991). Discourse on the development of EEG diagnostics and biofeedback for attention-deficit/hyperactivity disorders. Biofeedback \& Self-Regulation, 16, 201-225.

Pestrue, J., Miller, D., \& Beagley, G. H. (1995). Comparison of limited EEG measurement in college students with and without diagnosed attention deficit disorder [Abstract]. Michigan Academician, 27, 349.

PosNER, M. I., \& OsGooD, G. W. (1980). Computers in the training of inquiry. Behavior Research Methods \& Instrumentation, 12, 87-95.

Rivers, M., Mullington, J., Stampi, C., \& Broughton, R. (1994). A program for studies of altered sleep-wake schedules and performance. Behavior Research Methods, Instruments, \& Computers, 26, 323-330.

Rosen, E. F., \& PetTy, L. C. (1992). Computer-aided instruction in a physiological psychology course. Behavior Research Methods, Instruments, \& Computers, 24, 169-171.

Sanchez, A. R., Miller, C. M., \& Beagley, G. H. (1997). Effects of caffeine consumption on the EEG activity of college students [Abstract]. Michigan Academician, 29, 391.

Scammon, M. E., Kennard, M. M., Stroebel, C. F., \& Glueck, B. C. (1981). A user-interactive graphics-based computer system for the analysis of the EEG. Behavior Research Methods \& Instrumentation, 13, 517-524.

TANSEY, M. A. (1990). Right the rhythms of reason, EEG biofeedback training as therapeutic modality in a clinical setting. Medical Psychotherapy, 3, 57-68.

WALSH, D. H. (1974). Interactive effect of alpha feedback and instructional set on subjective state. Psychophysiology, 11, 428-435.

\section{NOTE}

1. BIOPAC Systems, Inc. 275 South Orange Avenue, Suite E, Goleta, CA 93117. Phone: (805) 967-6615.

(Manuscript received October 18, 1997; revision accepted for publication February 25, 1998.) 